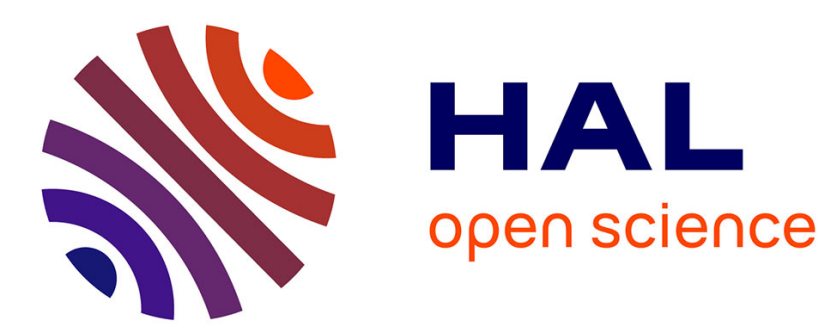

\title{
Patience and time consistency in collective decisions
} Laurent Denant-Boemont, Enrico Diecidue, Olivier L'haridon

\section{To cite this version:}

Laurent Denant-Boemont, Enrico Diecidue, Olivier L'haridon. Patience and time consistency in collective decisions. Experimental Economics, 2017, 20 (1), pp.181-208. 10.1007/s10683-016-9481-4 . halshs-01306949

\section{HAL Id: halshs-01306949 \\ https://shs.hal.science/halshs-01306949}

Submitted on 25 Apr 2016

HAL is a multi-disciplinary open access archive for the deposit and dissemination of scientific research documents, whether they are published or not. The documents may come from teaching and research institutions in France or abroad, or from public or private research centers.
L'archive ouverte pluridisciplinaire HAL, est destinée au dépôt et à la diffusion de documents scientifiques de niveau recherche, publiés ou non, émanant des établissements d'enseignement et de recherche français ou étrangers, des laboratoires publics ou privés. 


\title{
Patience and Time Consistency in Collective Decisions*
}

\author{
Laurent Denant-Boemont ${ }^{\dagger}$, Enrico Diecidue ${ }^{\ddagger}$, Olivier l'Haridon ${ }^{\S}$
}

January 5, 2016

\begin{abstract}
We present experimental evidence regarding individual and group decisions over time. Static and longitudinal methods are combined to test four conditions on time preferences: impatience, stationarity, age independence, and dynamic consistency. Decision making in groups should favor coordination via communication about voting intentions. We find that individuals are neither patient nor consistent, that groups are both patient and highly consistent, and that information exchange between participants helps groups converge to stable decisions. Finally we provide additional evidence showing that our results are driven by the specific role of groups and not by either repeated choices or individual preferences when choosing for other subjects.
\end{abstract}

JEL codes: C92, D90, D03.

Keywords: Time Preferences, Dynamic Consistency, present-bias, Group Decisions.

*We thank Aurelien Baillon, Nicolas Houy, Vincent Merlin, Amnon Rapoport, Jeeva Somasundaram, Karine Van Der Straeten, Marie-Claire Villeval and Peter Wakker for helpful comments. We also thank Elven Priour for programming the script and organizing the sessions.

†University Rennes 1 - CREM, Place Hoche, Rennes, France, email: laurent.denant-boemont@univrennes1.fr.

${ }^{\ddagger}$ INSEAD, Boulevard de Constance, Fontainebleau, France, email: enrico.diecidue@insead.edu.

§University Rennes 1 - CREM, Place Hoche, Rennes, France: olivier.lharidon@univ-rennes1.fr. 


\section{Introduction}

\subsection{Overview}

Most economic models rely on the assumption that individuals and organizations are consistent in their choices over time. Two central restrictions on time preferences - namely, stationarity and dynamic consistency - guarantee that some form of consistency is achieved in decisions (Strotz, 1955; Bleichrodt et al., 2009). These conditions are necessary if consistency is to be exhibited in the choices of an individual decision-maker (Halevy, 2015) or of several individuals coordinating on a group intertemporal decision (Jackson and Yariv, 2014). The same conditions must also be satisfied by any policy maker (Caplin and Leahy, 2004). Households, boards, committees, and teams are examples of groups that need to deliberate and coordinate their actions on important decisions that have a time dimension. Such decisions include those related to retirement and saving, education and health care, investments, providing effort and public goods, and building reputations.

Behavioral research on group decision making has shown that, comparatively speaking, groups are more likely to make rational choices whereas individuals are more likely to behave in a boundedly rational manner (Cooper and Kagel, 2005; Charness and Sutter, 2012; Maciejovsky et al., 2013). Hence the expectation is that intertemporal decisions made by a group are more consistent than those made by an individual. For instance, Charness and Sutter (2012) suggest that an individual who is prone to dynamic inconsistency in saving for retirement might achieve a better retirement outcome through participation in group decision making. Such participation could result in a better intertemporal decision with benefits that might compensate for the costs associated with delegating part of the decision.

There is little empirical evidence on group decision making in intertemporal choice. Yet numerous theoretical papers are devoted to group decision making and the aggregation of time preferences. Under such aggregation, these papers predict that a collective decision process will generally yield inconsistent choices over time even if group members are individually consistent (Gollier and Zeckhauser, 
2005; Zuber, 2010; Jackson and Yariv, 2015); if so, then the consequence could be inefficient behavior (Schaner, 2015). Empirical evidence on the aggregation of individual time preferences supports this view. For example, Jackson and Yariv (2014) report that a large majority of subjects acting as social planners are presentbiased and that only $2 \%$ of them exhibit consistent behavior.

The within-subject experiment described in this paper yields new lab evidence on the outcome resulting from individual and collective decisions. Following Halevy (2015), we combined static and longitudinal experimental methods to address the issue of stationarity and consistency of time preferences but without committing to a particular functional representation. More specifically, we tested four conditions on time preferences at both the individual and group levels: impatience, stationarity, age independence, and dynamic consistency. For group decisions, we designed a coordination mechanism based on majority voting preceded by a deliberation phase among the participants.

Our main results can be summarized as follows. In line with the existing literature on intertemporal choice, individuals were impatient and tended to deviate from consistent behavior. In contrast, groups typically made patient and highly consistent decisions; those decisions were based on majority voting after a long sequence of information exchange between group members through a series of straw polls. We observed that our coordination mechanism helped the groups to converge and to make both stable and dynamically consistent decisions. Because our results could have been driven by several confounding factors, we also implemented a series of additional treatments. These robustness checks showed that no such factors (i.e., repetition, voting, or choosing for others) can explain the high degree of patience and consistency displayed by the groups in our experiment.

\subsection{Literature Review}

Following Samuelson (1937) and Fishburn and Rubinstein (1982), a large part of the theoretical literature on time preferences builds on discounted utility and additively separable functional forms that assume a separation between value and delay 
in assessing temporal sequences of outcomes. A typical example is the exponential discounting utility model, which assumes stationarity of time preferences and serves as the workhorse of many economic models. The discounted utility model's representation of time preferences has the additional advantage of facilitating empirical measurements. With an extra assumption on the linearity of utility, measures of discount factors and discount rates can be carried out by way of simple experiments (Thaler, 1981; Coller and Williams, 1999). If one instead assumes nonlinear utility then measurements become more sophisticated yet also more complex (Andreoni and Sprenger, 2012b). All these measures share the potential descriptive limitations of the discounted utility model. If this model misrepresents time preferences, then so do all measurements based on that model. An alternative route is proposed by Rohde (2010) and Halevy (2015). These authors demonstrate that several basic properties of time preferences - including conditions on stationarity, dynamic consistency, and age independence - can be inferred empirically from direct conditions on preferences and also without committing to a specific functional representation of preferences. Our experiment follows that route and focuses on the basic conditions of choice over time without assuming any particular functional form.

The empirical literature on time preference has elicited an extremely wide variety of discount rates. Frederick et al. (2002) report elicited discount rates ranging from less than 1\% (Thaler, 1981) to more than 1,000\% (Holcomb and Nelson, 1992). Furthermore, individuals often exhibit present-bias and thus violate stationarity (Benzion et al., 1989; Kirby and Maraković, 1995; Bleichrodt and Johannesson, 2001; DellaVigna, 2009). However, more recent studies show that experiments can limit this well-established stylized fact - at least for monetary choices - by controlling for transaction costs and payment risk (Andreoni and Sprenger, 2012a; Augenblick et al., 2015). Stationarity is the key axiom underlying the discounted utility model's standard hypothesis of a constant discount rate. A decision exhibits 'stationarity' when it does not change in response to uniformly delayed receipts.

Stationarity should be distinguished from "dynamic consistency", under which a decision regarding the future made at one time is not changed at a later time. Testing for dynamic consistency therefore requires a longitudinal experimental de- 
sign (Horowitz, 1992; Sayman and Öncüler, 2009; Casari and Dragone, 2015; Meier and Sprenger, 2015), which explains the relative scarcity of experimental studies devoted to dynamic consistency. Those that do exist report mixed results. On the one hand, Horowitz (1992) and Meier and Sprenger (2015) report time consistency at the aggregate level but not at the individual level. Giné et al. (2014) observe $65 \%$ of study participants to be dynamically inconsistent - despite being reminded of their past choices - and Kang and Ikeda (2014) report non-negligible time variations in longitudinal survey measures of time preferences. ${ }^{1}$ On the other hand, Sayman and Öncüler (2009) find no evidence in favor of time inconsistency for short delays. Halevy (2015) report that $48 \%$ of the subject were time consistent. Augenblick et al. (2015) report that while $60 \%$ of their subjects were time consistent in monetary choices, that percentage declined to $25 \%$ for time consistency in real-effort tasks.

Evidence on group choice over time mainly concerns impatience. Available studies suggest that groups are more patient than their individual members. For example, individuals are more patient when making a joint decision with a partner than when making a decision for themselves. This statement holds whether the group consists of a decision-making real-life couple (Carlsson et al., 2012) or an experimental 'artificial' couple (Shapiro, 2010). Carlsson et al. (2012) also find that couple-made decisions violate stationarity. For larger groups, collective patience has been reported in groups of three to seven people (Shapiro, 2010; Denant-Boemont and Loheac, 2011).

Coordination mechanisms are central to group decision making. The most frequently used mechanisms in experiments are majority voting and unanimity. For example, Denant-Boemont and Loheac (2011) implement an unanimity rule in collective choice over time and find that it generates more patient choices than does majority voting. Unanimity does have some undesirable features, however. First, the length of the decision process is unknown; it differs among groups and also by decision. Accommodation is crucial for arriving at a unanimous group decision, and

\footnotetext{
${ }^{1}$ Meier and Sprenger (2015) also report non-negligible time-variations in experimental measures.
} 
the number of rounds needed to reach that stage is indeterminate. Moreover, as reported by Viscusi et al. (2011), the extent of accommodation is greater with majority than with unanimous decisions. Second, Gerardi and Yariv (2007) show that unanimity restricts the domain of implementable outcomes and eliminates some possible outcomes that could be achieved by other, intermediate coordination mechanisms - for example, the simple-majority voting rule. Majority voting is seldom enough to achieve efficiency. Goeree and Yariv (2011) demonstrate experimentally that collective deliberation can affect collective choice under various voting mechanisms. In particular, voting without deliberation tends to make voters more strategic, in which case voting behavior is more contingent on institutional rules. At the opposite extreme, unrestricted deliberation among group members renders communication itself more important than the issues being voted on. This result suggests that a majority-vote collective decision process incorporating initial communication over voting intentions may help participants coordinate more effectively when making a collective choice. Our experiment implements just such a collective decision process for choice over time.

The paper proceeds as follows. Section 2 presents the setting of the experiment and offers some theoretical background on time preferences. Section 3 summarizes the experimental results, and Section 4 concludes.

\section{Background and Experimental Design}

The purpose of the experiment was to compare the results achieved by outcomes resulting from collective and individual decisions over time. In a protocol similar to the one used by Halevy (2015) for individual decision making, we combined six indifference tasks to test four conditions on time preferences: impatience, stationarity, age independence, and dynamic consistency. Whereas Halevy's paper focuses on individual decision making, we measure indifferences at both the individual and the group level.

For the baseline experiment, we recruited 60 subjects from University of Rennes, France, and asked them to state their preferences between different pairs of timed 
outcomes in three regularly spaced experimental sessions. Each pair of timed outcomes proposed a choice between a smaller-sooner option and a larger-later option. Half of the decisions were individual ones and half were collective. For collective decisions, subjects were randomly assigned to twelve groups of five people each. Group membership remained identical across all decisions and all experimental sessions. Experimental instructions are described in Appendix B.

\section{$2.1 \quad$ Experimental Tasks}

\section{Summary}

Table 1 summarizes the choices between pairs of timed outcomes that were presented to subjects in the baseline experiment. This table shows the individual choices; choices for five-member groups were identical except for the $€ 100$ outcome, which for groups was multiplied by a factor of 5 . Choices were spread across three experimental sessions. Inspecting Table 1 reveals a number of similarities between the proposed choices. For example, the table's first row shows the same choice, but made at three different times. In Session 1 and Session 2, the second row corresponds to the first row except that receipts are both delayed by 4 weeks. Finally, the choices proposed in the first row for Session 2 and Session 3 correspond to the choices proposed (respectively) in the second row for Session 1 and Session 2 respectively. These similarities will be used to test basic conditions on time preferences. 


\begin{tabular}{lll}
\hline \hline Session 1 & Session 2 (4 weeks later) & Session 3 (4 weeks later) \\
\hline amount at present vs. $€ 100$ & amount at present vs. $€ 100$ & amount at present vs. $€ 100$ \\
in 4 weeks & in 4 weeks & in 4 weeks \\
\hline amount in 4 weeks vs. $€ 100$ & amount in 4 weeks vs. $€ 100$ & \\
in 8 weeks & in 8 weeks & \\
\hline amount at present vs. $€ 100$ & & \\
in 8 weeks & & \\
\hline \hline
\end{tabular}

Table 1: Summary of the individual choices between timed outcomes faced by subjects in each of three experimental sessions.

Note: All rewards were paid out after a one-day waiting period.

\section{Decisions}

We consider the decision maker - either an individual or a group - faced with choosing between timed outcomes. A timed outcome $(t, x)$ results in the receipt of a positive monetary outcome $x \in X^{+}$at date $t \in T$, where $X^{+}$represents the set of consequences and $T$ the set of future dates. The purpose of the experimental tasks shown in Table 1 was to elicit indifference values between a smaller-sooner time outcome and a larger-later one. We therefore use $s$ with reference to the most immediate (smaller-sooner) reward and $\ell$ with reference to the most delayed (largerlater) reward. Indifference values were elicited through a series of choice questions in order to determine the sooner outcome $\mathbf{x}$ for which a subject was indifferent with respect to a given later outcome:

$$
(s, \mathbf{x}) \sim(\ell, y)
$$

Outcome $y$ was kept constant during elicitation and across sessions; it was equal to $€ 100$ in individual decisions and to $€ 500$ in collective decisions. Delays $s$ and $\ell$ were varied across decision tasks to build testable conditions on time preferences.

Indifferences were elicited as follows. For each pair of timed outcomes, subjects were faced with a choice between a series of timed outcomes: option A (the largerlater outcome) and option B (the smaller-sooner outcome). Each subject was asked, 
immediately after switching from one option to the other, to quantify their indifference between the two options. For this purpose, the screen displayed a scrollbar (see Appendix C, Figure 7) that enabled subjects to specify their indifference points to the $€ 1$ level of precision. This method is known to yield more reliable indifference values than do procedures that ask respondents directly for those values (Bostic et al., 1990; Noussair et al., 2004); it is also the usual practice employed in the literature (for a review, see Takeuchi, 2011).

The elicitation process was repeated for each elicited indifference, and the resulting experimental data are characterized formally defined in Table 2. Half of the indifferences were elicited at the level of individual decisions and half at the level of collective decisions. To control for order effects between individual and collective tasks, individuals preceded groups in only two thirds of the sessions, and the reverse order was implemented in the remaining one-third. Because we focus on the difference between individual and collective decisions, we kept the same order (corresponding to Table's 1 row order) within the individual and collective decisions in all three experimental sessions. Hence any order effect that did arise would not affect the difference between individual and collective decisions.

\begin{tabular}{ccc}
\hline \hline Session $1(t)$ & Session $2(t+\Delta)$ & Session $3(t+2 \Delta)$ \\
\hline$\left(s, \mathbf{x}_{\mathbf{1}}^{\mathbf{1}}\right) \sim_{t}(\ell, y)$ & $\left(s+\Delta, \mathbf{x}_{\mathbf{2}}^{\mathbf{1}}\right) \sim_{t+\Delta}(\ell+\Delta, y)$ & $\left(s+2 \Delta, \mathbf{x}_{\mathbf{3}}^{\mathbf{1}}\right) \sim_{t+2 \Delta}(\ell+2 \Delta, y)$ \\
$\left(s+\Delta, \mathbf{x}_{\mathbf{1}}^{\mathbf{2}}\right) \sim_{t}(\ell+\Delta, y)$ & $\left(s+2 \Delta, \mathbf{x}_{\mathbf{2}}^{\mathbf{2}}\right) \sim_{t+\Delta}(\ell+2 \Delta, y)$ & \\
$\left(s, \mathbf{x}_{\mathbf{1}}^{\mathbf{3}}\right) \sim_{t}(\ell+\Delta, y)$ & & \\
\hline \hline
\end{tabular}

Table 2: Elicited indifferences in each session.

Notes: For each session, decision times are given in parentheses and experimental data are shown in bold. Each indifference is elicited by varying the sooner outcome until it reaches the indifference value; $y=€ 100$ in individual decisions and $y=€ 500$ in collective decisions, $\Delta=\ell=4$ weeks, $s=$ day of the first session. Rewards were paid out after a one-day waiting period. 


\section{Incentives}

Each subject was paid $€ 20$ for participating in three experimental sessions. This appearance fee was paid at the end of the last session to ensure that participants would show up for all three of them. We also implemented a between-subject, random-task incentive scheme following a Becker-De Groot-Marschak (BDM) procedure. Before starting the experiment, subjects were informed that they might be selected to play one of their choices for real and could win as much as $€ 100$ per session depending on their choices. In order to prevent immediacy effects, we included a front-end delay: all rewards were paid out after a one-day waiting period. The BDM procedure was implemented as follows. At the end of each experimental session, the computer selected one decision task at random. For that task, the computer selected one possible decision between paired outcomes at random. To build this decision, an integer $d$ within the range of possible indifference values was selected at random and the decision used for payment was

$$
(s, d) \text { vs. }(\ell, y) \text {. }
$$

An indifference value $x$ means that the decision maker prefers the larger later payment as long as the smaller sooner does not offer at least $x$. If $d$ is lower than $x$, one could infer that the selected choice should be $(\ell, y)$ rather than $(s, d)$, and the larger later payment $(\ell, y)$ was played out for real. Conversely, if the indifference value $x$ were lower than $d$ then one could infer that the selected choice should be $(s, d)$, rather than $(\ell, y)$, and then the smaller sooner payment $(s, d)$ was played out for real.

Because the BDM procedure was repeated for each of the three experimental sessions, each subject could win a total amount of $€ 300$ over the three experimental sessions. $^{2}$ The probability of being selected in each session was independent and identically distributed and was equal to one fifth. Selected subjects played their choice for real at the end of each experimental session. We used a front-end delay to

\footnotetext{
${ }^{2}$ We could not completely rule out wealth effects. For individuals who are paid for real at $\ell+\Delta$, those previous gains might have affected behavior in Session 3. Since only three subjects met this condition, it is reasonable to assume that wealth effects did not bias our results.
} 
minimize the possibility of perceived differences between the two payoff options with respect both to transactions costs and to the risk associated with future payments. This single-day front-end delay was also compatible with the payment scheme. One difficulty for any experiment involving a trade-off between immediate and future rewards is that subjects might not trust the experimenter to provide the promised future rewards in a timely fashion. Toward the end of establishing trustworthiness in the experiment and reducing fears of manipulation, all future payments were warranted - and transferred directly to the subject's bank account - by the National Public Treasury.

\section{Coordination Mechanism for Group Decisions}

Within a given set of sessions, each subject participated in both individual and group decision making. For group decisions, participants were aware from the beginning that any group decision would be reached by a majority rule and would lead to an 'equal sharing of rewards' rule. Each subject was randomly matched with four other

subjects at the beginning of the first session. We used a so-called partner-matching design: each group remained the same during the entire experiment. Before reaching a collective decision, group members were allowed to exchange information about their preferences. The decision procedure took the form of a sequence of four successive straw polls. Before each poll, every subject declared (to the other group members) her own indifference value $x$ such that $(s, x) \sim_{t}(\ell, y)$; this indifference value corresponds to the collective outcomes $x$ and $y$ being equally shared among group members. At each step in the sequence, subjects were informed of all members' indifference values prior to the next straw poll. Group members thus had four opportunities to indicate their favorite option.

The information each subject received at the end of each sequence is displayed in Figure 9 in the Appendix. The identity of each group's member was referred to by a color (brown, blue, purple, grey and beige). The colors remained the same for a given collective choice, but they were changed randomly between sequential vote processes in order to ensure anonymity and preclude any reputation effects. 
In the last step of the collective decision process, subjects were required to choose collectively: they had to reach an agreement by majority voting. At the end of the fifth sequence, the indifference amounts for the most immediate reward were ranked from the lowest to the highest. The median value - that is, the option preferred by the majority of the group members — was then applied to the entire group.

\subsection{Time Preferences}

We assume that the decision maker has preferences over the set of timed outcomes $T \times X^{+}$. Following Halevy (2015), we endow the decision maker with a sequence $\left[\succsim_{t}\right]_{t=0}^{\infty}$ of complete and transitive binary relations defined over timed outcomes. We assume that preferences satisfy the usual continuity and monotonicity assumptions, and we use conventional notation to express the decision maker's preference; thus $\succ_{t}, \succsim_{t}$, and $\sim_{t}$ represent the relations of (respectively) strict preference for, weak preference for, and indifference between the sequences of timed outcomes at decision time $t$. Based on the elicited indifferences shown in Table 2, we investigate four conditions related to time preferences: impatience, stationarity, age independence, and dynamic consistency. We begin by defining these conditions formally as follows.

Definition $1 \succsim_{t}$ exhibits impatience if for any $x$ and every $t<s<\ell$,

$$
(s, x) \succ_{t}(\ell, x) .
$$

It follows from Definition 1 that impatience can also be defined as the indifference at date $t$ between a small outcome $x$ received soon (at date $s$ ) and a larger outcome $y$ received later (at date $\ell$ ). So besides measuring impatience via comparison of $x$ and $y$, the experiment also manipulates delay $\ell$ to measure the "shape" of the decision maker's impatience. For each row $i$ and column $j$ in Table 2, impatience holds whenever $x_{j}^{i}<y$.

Definition $\mathbf{2} \succsim_{t}$ is stationary if, for $x, y$ and every $s, \ell, \Delta$ : 


$$
(s, x) \sim_{t}(\ell, y) \Longleftrightarrow(s+\Delta, x) \sim_{t}(\ell+\Delta, y)
$$

Stationarity means that a decision made at date $t$ does not change when each option's payoff is delayed by the same amount of time. Under stationarity, then, the choice between two timed outcomes depends only on the time distance $\ell-s$ between them. Stationarity is an important property of time preference and is one of the key axiom in Koopmans' axiomatization of discounted utility. ${ }^{3}$ Stationarity reflects constant impatience, and it has been extensively investigated in the experimental literature (see Frederick et al. (2002)). Decreasing impatience, or present-bias, is the individual violation of stationarity most often identified in behavioral economics. ${ }^{4}$

In the first two columns of Table 2, comparing the first two rows provides a direct test of the stationarity condition stated by Definition 2 (without assuming the discounted utility model). If preferences are stationary, then we should observe $x_{1}^{1}=x_{1}^{2}$ in column 1 and $x_{2}^{1}=x_{2}^{2}$ in column 2 . The farther from zero is the difference $x_{j}^{2}-x_{j}^{1},(j=1,2)$, the greater are the violations of stationarity.

Definition $3\left[\succsim_{t}\right]_{t=0}^{\infty}$ satisfies age independence if for $x, y$ and every $s, \ell, \Delta$ :

$$
(s, x) \sim_{t}(\ell, y) \Longleftrightarrow(s+\Delta, x) \sim_{t+\Delta}(\ell+\Delta, y) .
$$

Under age independence, which is also and more typically known as "time invariance" (Halevy, 2015), a decision made at date $t$ remains the same at date $t+\Delta$ if all receipts are delayed by the same amount of time. According to this condition,

3 That axiomatization is based on five axioms - three technical conditions (continuity, sensitivity and boundedness), stationarity and an independence axiom - applied to time sequences (noncomplementarity). Bleichrodt et al. (2008) clarify Koopmans' axioms, especially independence and stationarity, and propose a clean and complete preference axiomatization of discounted utility.

${ }^{4}$ In the discounted utility model, violations of stationarity are not compatible with an exponential discount function; hence they are represented by a wide range of alternative discount functions. Of these, the most widely used are hyperbolic discount functions (Phelps and Pollak, 1968; Loewenstein and Prelec, 1992). Yet violations of stationarity can be accommodated also by nonhyperbolic discount functions (Bleichrodt et al., 2009), which can more flexibly incorporate increasing impatience. 
preferences are independent of calendar time. The experimental test of age independence manipulates the choice node by moving the choice date from $t$ to $t+\Delta$ and the front-end delay from $s$ to $s+\Delta$. In each row of Table 2, between-column comparisons provide a direct test of the age independence condition stated by Definition 3 . If preferences satisfy age independence then we should observe $x_{1}^{1}=x_{2}^{1}=x_{3}^{1}$ in row 1 and $x_{1}^{2}=x_{2}^{2}$ in row 2 . The larger the absolute differences between the $x$-values, the greater the violations of age independence.

Definition $4\left[\succsim_{t}\right]_{t=0}^{\infty}$ satisfies dynamic consistency if for $x, y$ and every $t+\Delta<s, \ell$ :

$$
(s, x) \sim_{t}(\ell, y) \Longleftrightarrow(s, x) \sim_{t+\Delta}(\ell, y)
$$

The state of dynamic consistency obtains provided a decision made at date $t$ for future timed outcomes remains the same for a given pair of timed outcomes when made at date $t+\Delta$. Our experiment therefore moves the choice date from $t$ to $t+\Delta$ while keeping the delay $s$ constant. Both Sayman and Öncüler (2009) and Read et al. (2012) propose similar designs but with a different nomenclature. ${ }^{5}$ In both of those papers, dynamic consistency is defined as longitudinal time consistency. Casari and Dragone (2015) refer to our violations of stationarity, dynamic consistency, and age independence as (respectively) static choice reversal, dynamic choice reversal, and calendar choice reversal. In Table 2 within-diagonal comparisons between the first two rows provide a direct test of dynamic consistency. If preferences satisfy dynamic consistency, then we should observe $x_{1}^{2}=x_{2}^{1}$ and $x_{2}^{2}=x_{3}^{1}$. The farther from zero are the differences $x_{1}^{2}-x_{2}^{1}$ and $x_{2}^{2}-x_{3}^{1}$ are, the greater are the violations of dynamic consistency.

Definitions 2, 3 and 4 are not independent because each pair of conditions implies the other. For example, Strotz (1955) proves that stationarity (Definition 2) and age independence (Definition 3) together imply dynamic consistency (Definition 4). It follows that stationarity and dynamic consistency are equivalent if and only if age independence is satisfied. These three definitions also show that time consistency

\footnotetext{
${ }^{5}$ Our "stationarity" is their "cross-sectional time consistency".
} 
and age independence together imply stationarity. As a result, violations of dynamic consistency lead to violations of stationarity if one assumes that age independence is satisfied. Yet if age independence is not satisfied then violations of dynamic consistency need not result in violations of stationarity. ${ }^{6}$

\subsection{Method}

The indifference values elicited in both individual and collective tasks were designed to test the four conditions (defined in Section 2.2) on time preferences. The first information provided by a given elicited outcome is the amount of revealed impatience. According to Definition 1, if the elicited outcome - that is, the "sooner" value - was strictly lower than (resp., was equal to) the "later" value, then the decision maker was considered to be impatient (resp., patient). The ratio of the elicited outcome to the later outcome yields a simple index of impatience: the lower the ratio, the greater the impatience with respect to a given decision.

By Definition 2, the difference $x_{j}^{2}-x_{j}^{1}, j=1,2$ provides a test for violations of stationarity; it can be used to construct a simple index of stationarity violations whereby the larger the deviations from zero, the greater the violations of stationarity. The index can be computed either at date $t$ (when $j=1$, the index is defined as $x_{1}^{2}-x_{1}^{1}$ ) or at date $t+\Delta$ (when $j=2$, the index if defined as $x_{2}^{2}-x_{2}^{1}$ ).

Violations of age independence (Definition 3) are revealed by an index based on the difference $x_{2}^{i}-x_{1}^{i}, i=1,2$. This index can likewise be computed from date $t$ (when $i=1$, the index is defined as $x_{2}^{1}-x_{1}^{1}$ ) or from date $t+\Delta$ (when $i=2$, the index is defined as $x_{2}^{2}-x_{1}^{2}$ ). Comparing between $x_{3}^{1}$ and $x_{2}^{1}$ yields another index of age independence.

Violations of dynamic consistency (Definition 4) can be similarly measured using an index based on the difference between $x_{j}^{2}$ and $x_{j+1}^{1}, j=1,2$. Values greater (resp. less) than zero indicate standard (resp. reverse) dynamic inconsistency. In

\footnotetext{
${ }^{6}$ For example, age independence is violated by a man who prefers one apple on his 21 st birthday to
} two apples the day after but in all other situations prefers two apples a day later. Such a decision maker exhibits dynamic consistency but not stationarity. 
Section 3, we use two-sided Student tests to check for violations of stationarity, age independence, an dynamic consistency. We checked for robustness via Wilcoxon signed-rank tests and the (unreported) results were similar. For the purpose of comparing individual and group decisions, we divided the indexes of stationarity, age independence and dynamic consistency by a factor of 5 when evaluating decisions made by (five-member) groups. The experimental tasks also allowed us to measure discount factors - albeit at the cost of assuming a linear discounted utility model. Under this assumption, any indifference $(s, x) \sim_{t}(\ell, y)$ results in the following equality: $\delta_{t}(\ell)=\delta_{t}(s) \frac{x}{y}$. If we use two indifferences whose delays $\ell$ differ, then the ratio between the respective $\delta_{t}(\ell)$-values yields an index that reflects what is known as the shape of impatience. More specifically, that ratio indicates whether the decision maker exhibits decreasing, constant, or increasing impatience.

Finally, we present two additional methods for analyzing collective choice. The first evaluates the efficiency of straw polls as a coordinating device. This measure compares the final vote to the last message sent to the other group members; it corresponds to the measure used by Forsythe et al. (1993) to test voting equilibria. The second method compares the group's final decisions to its members' individual preferences. We assess the cost of deviating from individual preferences by simulating, for each collective decision, the corresponding decision that a benevolent planner would make by aggregating individual indifferences.

\section{Results}

\subsection{Time Preferences}

\section{Impatience}

Elicited indifference values make for a simple way to characterize the decision behavior of individuals and of groups. Altogether, $42.3 \%$ of individual decisions were patient; the proportion rose to $80.6 \%$ for groups. Group decisions were statistically more likely to be patient than the equivalent individual decisions (binomial test, $p<0.01)$. In order to investigate the pattern of discounting behaviors more thor- 
oughly, we first classified individual and groups based on their answers. A decision maker was classified as impatient (resp. patient) if at least four out of six indifference values yielded an impatient (resp. patient) answer; otherwise, the decision maker was classified as mixed. On the one hand, a majority of individual decision makers were impatient - although a significant minority (30.4\%) were patient. On the other hand, a large majority (83.4\%) of the groups were classified as patient. Thus, collective behavior based on majority voting did not mirror individual behavior.

Figure 1 shows the distribution of average monthly discount rates inferred from the five decisions involving a 4-week delay. The solid line represents the cumulative distribution function for the group discount factors. This cumulative distribution function orders the data by group from the more patients groups to the less patient groups. In addition to group discount factors, for each group, the figure also shows the discount factors corresponding to individual decisions (black dots) as well as the discount factors corresponding to final votes (gray crosses).

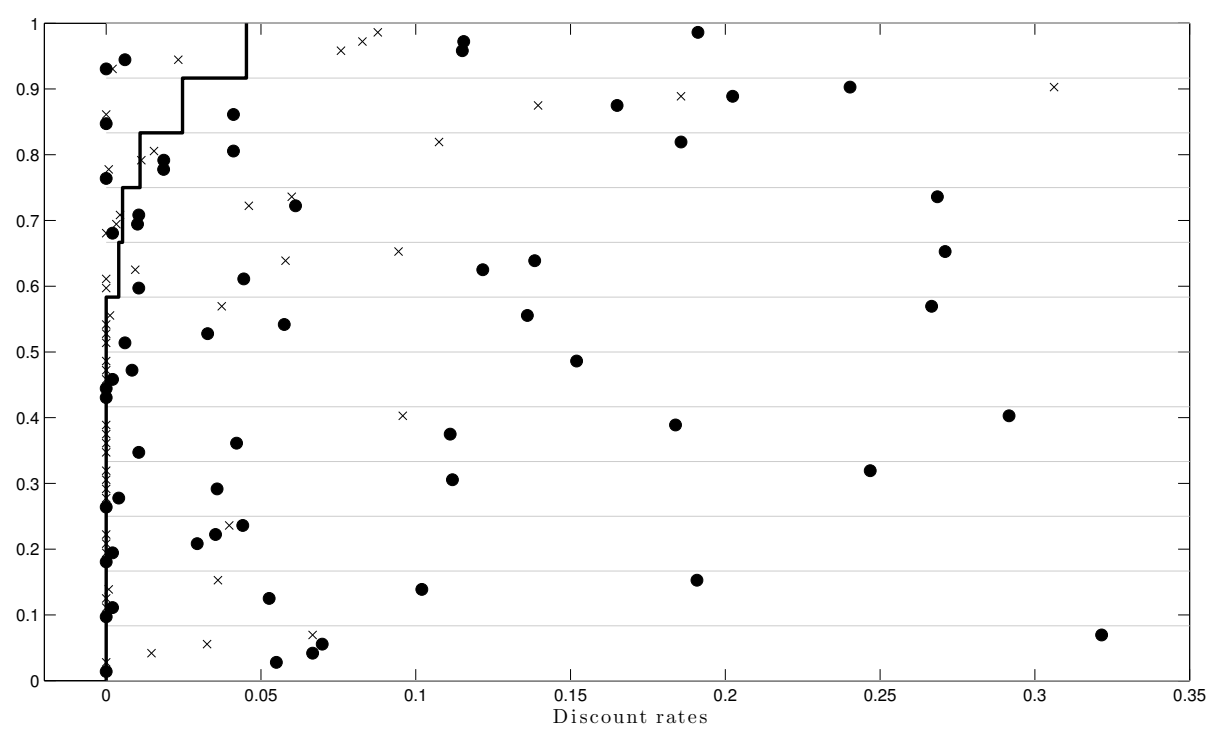

Figure 1: Average monthly discount rate for 4-week delays.

This graph plots the cumulative distribution function for group discount factors, and horizontal gray lines are used to separate the groups. For each group, black dots mark the average discount factors of its individual members and gray crosses indicate the average votes of those members. 
It is clear from this figure that group decisions differ from individual decisions and that group decisions were in general much more patient that those made by individuals, who were usually impatient. It is also clear that, within a group setting, subjects did not vote in accordance with their individual preferences.

In addition, we compared discount factors for indifference values elicited at the same date for a delayed outcome with delays $\Delta=4$ weeks and $2 \Delta=8$ weeks. The difference gives information about the shape of impatience in our experiment. If the discount factor for a 8-week delay was proportionally higher than (resp. equal to, lower than) the elicited discount factor for a 4-week delay, then the decision maker was said to show decreasing (resp. constant, increasing) impatience. Figure 2 shows the distribution of differences in discount rates as well as their values for individual group members. In this figure, the left part of the $x$-axis corresponds to decreasing impatience (as is usually reported by the experimental literature); the right part of the $x$-axis corresponds to increasing impatience. Decreasing impatience was dominant $(58 \%)$ for individual decisions. Epper et al. (2011) obtain much the same proportion (54\%) but Andreoni and Sprenger (2012a) find that fewer than $17 \%$ of subjects satisfy diminishing impatience. So even when controlling for transactions costs and payment risk, we still find behavior compatible with a quasi-hyperbolic model at the individual level for a slight majority of subjects. At the same time, however, we also observe that a not insignificant (15\%) proportion of individual choices are characterized by increasing impatience, which is not compatible with the quasi-hyperbolic model. In line with the results presented previously, constant impatience (characterized by a zero difference in discount rates) was dominant for collective decisions. Figure 2 clearly indicates that constant impatience at the group level cannot be entirely explained by group member's constant impatience. It also shows that final votes (represented by gray crosses) did not align exactly with individual preferences. 


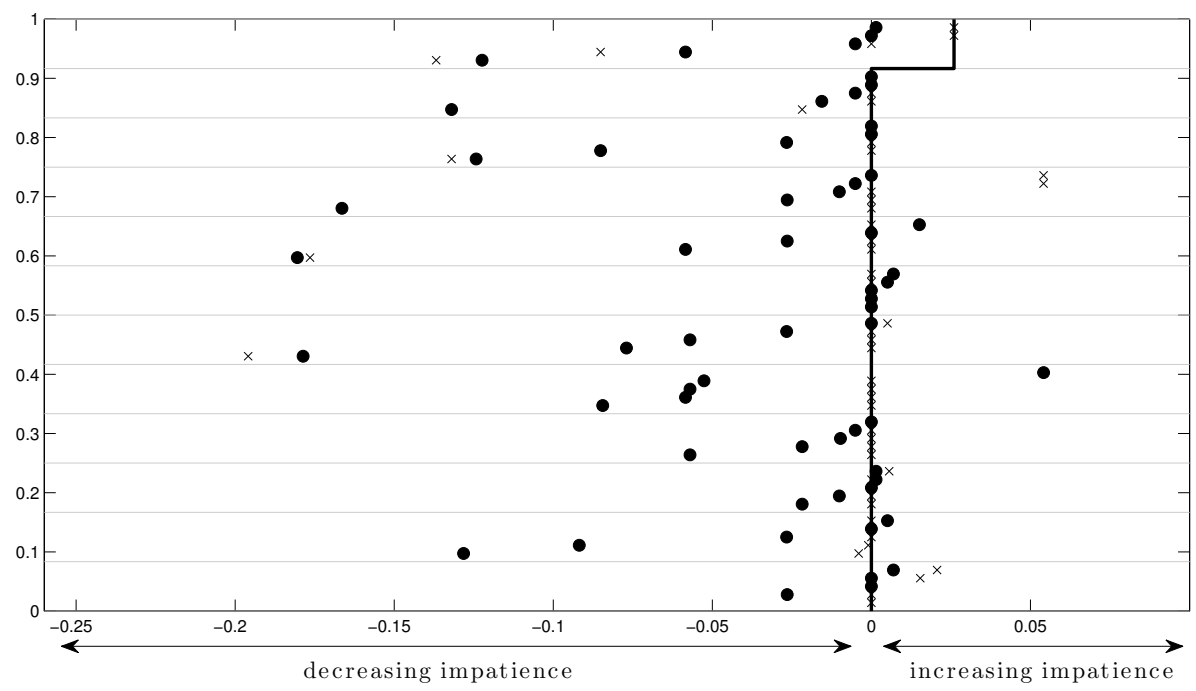

Figure 2: Shape of impatience for individuals (dots) and groups (solid line).

This graph plots the cumulative distribution function for differences in the group monthly discount factors elicited with a 4-week delay and a 8-week delay. The groups are separated by horizontal gray lines. For each group, black dots mark the average discount factors of its individual members and gray crosses indicate the average votes of those members (The figure does not show one outlier with a highly negative difference).

\section{Stationarity}

Stationarity predicts the equality of the elicited values in the upper two rows in Table 2. Figure 3 shows the distributions of stationarity indexes for individuals and groups. If the index has a positive (resp. negative) value, then individuals were less (resp. more) patient for a decision made at date $t$ than when the receipts were delayed by the same amount of time. A negative value of the index of stationarity mean that individuals were more patient for a decision made at date $t$ than when the receipts were delayed by the same amount of time. According to the literature, we should expect positive values to predominate. Figure 3 shows this was indeed the case at the individual level - especially in Session 2, when stationarity was evaluated at $t+\Delta$. It is clear from the figure that groups generally exhibited more stationarity than did individuals, who generally had non-zero indexes. The vast majority of groups replicated the same patient decision in all of their deliberations and behaved as zero- 
discounting maximizers. The picture is different for decisions made by individuals, whose behavior was incompatible with stationarity. In this respect, the minority of subjects who made patient choices coexisted with the majority of impatient subjects who did not and therefore violated stationarity. ${ }^{7}$

(a) stationarity indexes at $t$

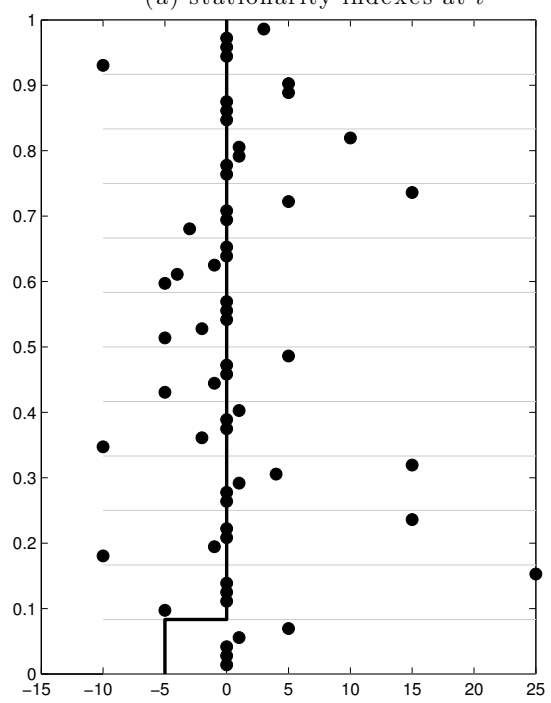

(b) stationarity indexes at $t+\Delta$

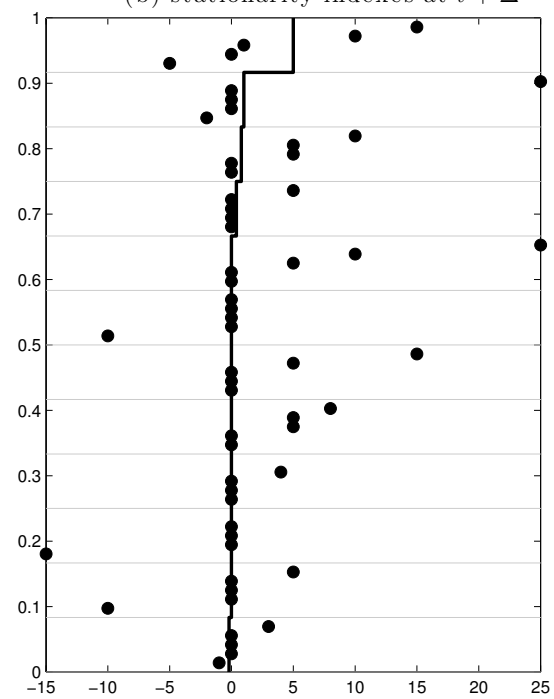

Figure 3: Stationarity indexes.

This graph plots the cumulative distribution function for the group indexes of stationarity at $t$ and $t+\Delta$. Horizontal gray lines separate the groups, and black dots mark the individual indexes of stationarity.

\section{Dynamic Consistency and Age Independence}

Dynamic consistency predicts the equality of the elicited values only for those cases in which the time of the decision changes. Age independence predicts the equality of the elicited values within rows. We found evidence of both dynamic consistency and age independence being violated by individual decisions but no such evidence regarding collective decisions. Figures 4 and 5 shows the distributions of (respectively) dynamic consistency indexes and age independence indexes for groups and

${ }^{7}$ The tables in Appendix A show the values of the indexes of stationarity, age independence, and dynamic consistency for both individuals and groups (and their significance levels). 
individuals. For dynamic consistency, a negative (resp. positive) index corresponds to decisions being less (resp. more) patient than planned in the previous session. Figure 4 reveals that dynamic consistency was achieved at the group level but not at the individual level. The difference was especially noticeable for sessions 2 and 3 , where negative values at the individual level predominated and so individuals were less patient than planned. This figure also shows the contrast - in terms of dynamically consistent decisions - between group-level homogeneity and individual-level heterogeneity within-group.

(a) dynamic consistency indexes at $t+\Delta$

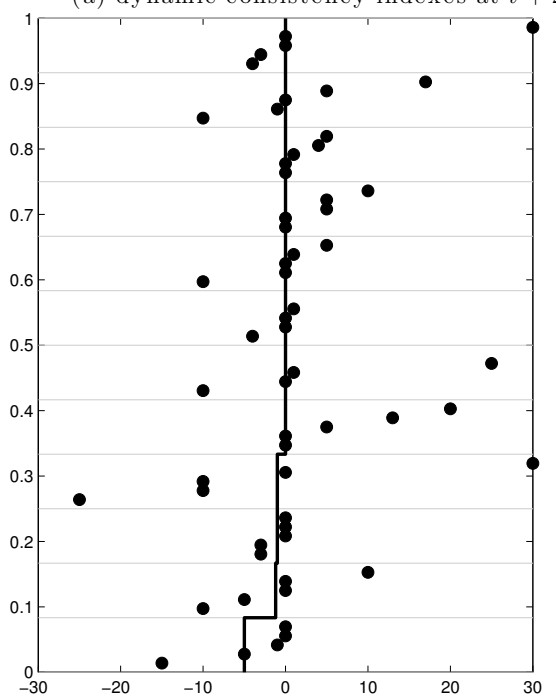

(b) dynamic consistency indexes at $t+2 \Delta$

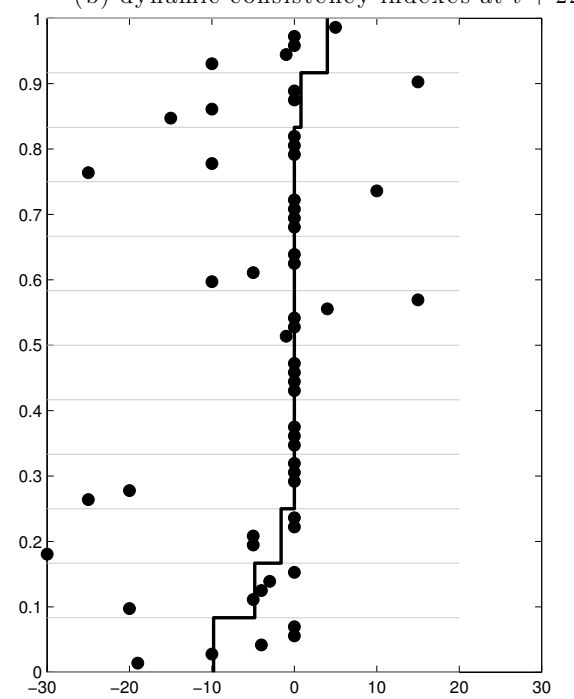

Figure 4: Dynamic Consistency indexes.

This graph plots the cumulative distribution function for the group indexes of dynamic consistency at $t+\Delta$ and $t+2 \Delta$. Horizontal gray lines separate the groups, and black dots mark the individual indexes of dynamic consistency.

Figure 5 establishes that age independence was achieved at the group level. Our findings on dynamic consistency and age independence were compatible with those on stationarity, which confirms that the the first two conditions together imply the third. In both cases, groups were highly time-consistent. There is evidence of age independence being violated at the individual level, especially with regard to $t+\Delta$. In that case, we found the average index to be significantly greater than 
zero, indicative of more patient decisions in later sessions. This result contrasts with the findings of Wölbert and Riedl (2013), who report hardly any violations of age independence in individual choices. No systematic pattern of group visà-vis individual decisions emerges from Figure 5. Collective age-independence is variously associated with different types of groups: those containing only positiveindex members, those with a mix of (say) three positive-index and two zero-index members, and those with only zero-index members.
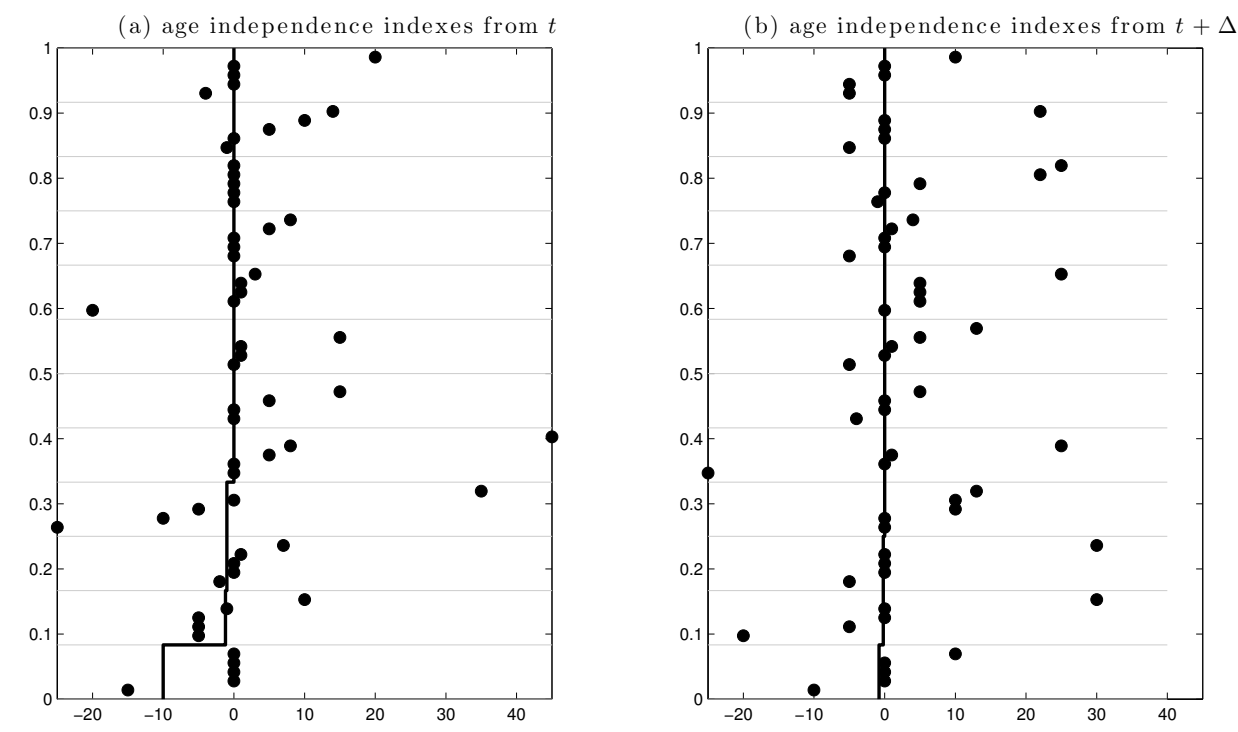

Figure 5: Age independence indexes.

This graph plots the cumulative distribution function for the group indexes of age independence at $t+\Delta$ and $t+2 \Delta$. Horizontal gray lines separate the groups, and black dots mark the individual indexes of age independence.

\subsection{Coordination Mechanism}

\section{Efficiency of Straw Polls}

The efficiency of straw polls in achieving coordination was assessed by comparing the final vote with the last message sent to the other group members. Overall, efficiency was high: $87.5 \%$ of the final votes were strictly identical to the intentions 
declared in the last straw poll. Efficiency declined between experimental sessions from $92.8 \%$ in session 1 to $81.9 \%$ in session 2 and $82.1 \%$ in session 3 . Nonetheless, we found no differences between the values cast as final votes and the intentions declared in the last straw poll (all $p>0.22, t$-tests). Figure 6 graphs the relation between values casted in the last straw poll and the final votes. Only a small portion of votes were above $(7.7 \%)$ or below $(4.8 \%)$ the value cast in the last straw poll.

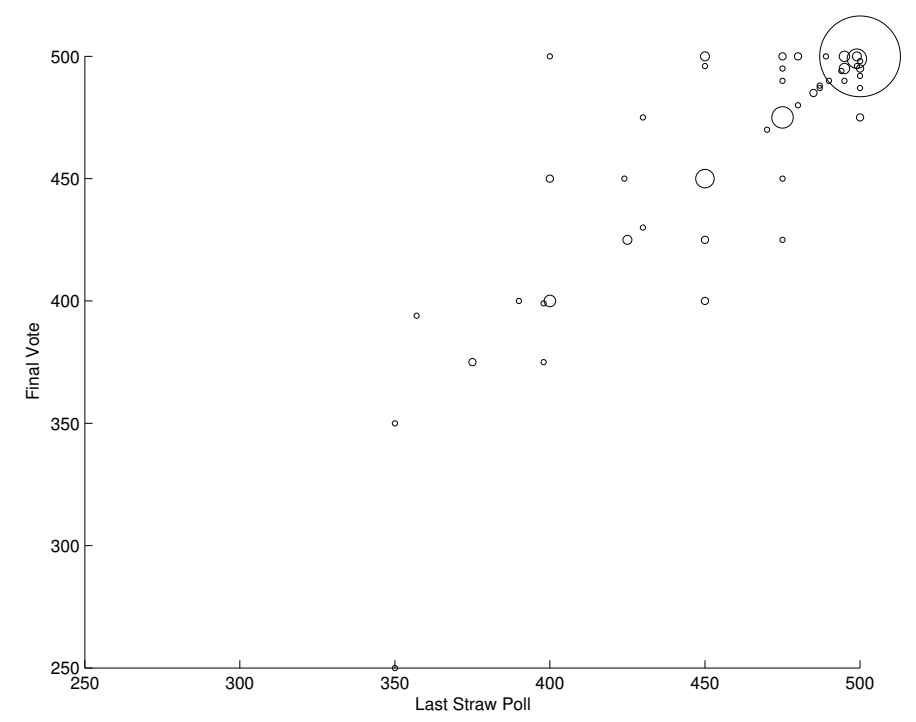

Figure 6: Efficiency in coordination.

This graph plots the values $x$ cast in the last straw poll against final votes. Circles' dimensions are proportional to the number of observations.

\section{Distance to Individual Preferences}

In order to compare collective decisions and individual preferences, we first evaluated the distance between the outcome of collective decisions and the elicited individual values. Overall, $35.8 \%$ of the final group decisions were identical to those made by individuals. This percentage was stable across sessions, which suggests that reaching a collective decision in choice over time may be nonnegligibly more expensive than relying on individual preferences. Among the final decisions, $97 \%$ corresponded to patient choices; even so, votes differed from individual values (all $p<0.01$ ). Slightly more than half $(54 \%)$ of decision choices were made more patiently by groups than 
by individuals. For a minority ( $8 \%$ ) of choices, the collective decision was actually more impatient than the corresponding individually preferred decision. For $78 \%$ of patient individuals, more than four out of six final decisions were in line with their individual preferences; in contrast, for no impatient individual was any collective decision in line with his individual preference.

One can also measure the distance to individual preferences by simulating the equivalent values that a benevolent planner would select for each decision. The simulation assumes that this planner can perfectly observe the elicited values at the individual level and aggregate them at the group level by summing individual values. ${ }^{8}$ We found that, on half of the measures, the utilitarian planner would implement a decision that is incompatible with stationarity (detailed results are given in Table 6 in Appendix A). Dynamic consistency and age independence were also violated by simulated choices of this type. These results replicate Jackson and Yariv's (2014) findings that the benevolent social planners do not make consistent choices. Our social planner results are strongly consistent with individual results and indicate that collective decisions differ from decisions based on criteria that sum up and/or average indifferences. These findings demonstrate also that group composition has no effect on the extent to which stationarity, age independence, or dynamic consistency are violated.

\subsection{Robustness}

Several confounding factors might have played a role in our results. First, the group decisions in our experiment resulted from a combination of voting and signaling through straw polls. To disentangle the effects of these factors, we ran two additional treatments to elicit indifference values $x_{1}^{1}, x_{1}^{2}, x_{1}^{3}$, with $N=60$ individuals each. We began by setting up a VoTiNG treatment based on majority voting without straw polls. In this treatment, we asked subjects to vote on a collective decision

\footnotetext{
8 Two subjects dropped out after session 1 and two more after session 2. The resultant missing data precluded our simulating a utilitarian criterion for three of the groups, which is why the simulation results are given only for nine of the twelve groups.
} 
but without any additional information on the others' preference for that decision. We then set up an INFORMED PLANNER treatment in which subjects individually decided for the whole group; in this treatment, subjects voted in a single straw poll before each decide alone - as a planner - for the group. The Voting treatment, which consists of a vote with no preliminary straw polls, allows us to identify a pure effect of voting on collective decisions.

The INFORMED PLANNER treatment, which consists of decisions being made for the group after a single straw poll, reveals the effect of providing some information on individual preferences. In that treatment, individuals decide alone for the whole group. Strict self-interest would call for the decision maker to align group outcomes with her individual preferences and so, if collective choice differs from individual choice, then decision-making subjects can be expected to account for the effects that their own choices have on others. We also implemented an UNINFORMED PLANNER treatment (with $N=20$ subjects) to check for the possibility that other-regarding considerations could play a role in group choices. In this treatment, subjects were asked to decide for the whole group while having no information on the others' preferences. If subjects' concerns about group outcomes are different from their own concerns, then their choices in a collective context should differ when made in an individual context.

According to Charness and Rabin (2002), three kinds of social preferences could explain why individuals are concerned about the payoff to others: efficiency concerns, aversion to inequity or reciprocity considerations. These concerns might be even stronger in settings (e.g., the PlanNer treatments) where individuals are required to decide not only for themselves but also for others. In our experiment, aversion to inequity could not play a role because the group payoff was equally shared among group members. Note also that any role played by reciprocity considerations would be minor owing to the low number of successive choice iterations. That being said, informational feedback between participants in the INFORMED PLANNER treatment could have been a source of reciprocity. We cannot rule this possibility out, but we did ensure anonymity by rematching colors within each group and thereby reduced that possible source of reciprocity. Observe that in the UNIN- 
FORMED PLANNER treatment there was no informational feedback during iterations, which precluded any reciprocity based on informational feedback.

We are thus led to conclude that social preferences are explained by the efficiency concern, implemented as a strategy to maximize the group's payoff. A planner opting for this strategy would always choose the larger-later option irrespective of his own individual preference. We found small support for this hypothesis $(p=0.45) .{ }^{9}$ We also ran several Probit regression models to measure the difference between the main experiment and the additional treatments. The first regression amounted to estimating a Probit model of impatience. For that purpose, the decision maker was classified as impatient (resp. patient) if at least two of the three indifference values $\left(x_{1}^{1}, x_{1}^{2}, x_{1}^{3}\right)$ yielded an impatient (resp. patient) answer. We next estimated a Probit model on stationarity; here the decision maker's behavior satisfied stationarity when $x_{1}^{1}$ equalled $x_{1}^{2}$. Each Probit model was estimated both for individuals and for collective decisions. Table 3 reports our regression results in the form of marginal effects (with the main experiment as the reference level).

This table reveals the effect of these additional treatments on individual and collective decisions. First, group decisions displayed significantly more patience as well as more stationarity in the main experiment than in the additional treatments. Neither voting or choosing alone (as a planner) for the whole group can explain the highly consistent decisions observed in the main experiment. However, we found that individual preferences were little affected by additional treatments. Individual stationarity, when measured at the subject level, does not differ significantly between the main experiment and the additional treatments. Thus our results indicate that neither efficiency nor other-regarding preferences is a real concern for participants acting as a planner: in both PlanNer treatments, individual choices do not differ significantly from group choices. Yet under the Voting treatment we observe - in line with previous literature (Schram, 2004) - a mild positive correlation between the group choice and the median of individual choices (Pearson correlation of 0.43).

\footnotetext{
${ }^{9}$ With regard to one of Session 1's three tasks (viz., elicitation of $x_{1}^{3}$ ), we found that group decisions were more patient than individual decisions $(p=0.04)$.
} 


\begin{tabular}{ccccc}
\hline \hline & \multicolumn{2}{c}{ Impatience } & \multicolumn{2}{c}{ Stationarity } \\
treatment & Individual & Groups & Individuals & Groups \\
\hline REPETITION & $0.233^{*}$ & - & -0.083 & - \\
& $(0.091)$ & - & $(0.127)$ & - \\
VOTING & 0.133 & $0.475^{* *}$ & -0.117 & $-0.454^{* *}$ \\
& $(0.080)$ & $(0.075)$ & $(0.090)$ & $(0.076)$ \\
INFORMED PLANNER & $0.167^{*}$ & $0.392^{* *}$ & -0.167 & $-0.420^{* *}$ \\
& $(0.078)$ & $(0.079)$ & $(0.088)$ & $(0.077)$ \\
UnINFORMED PLANNER & 0.083 & $0.525^{* *}$ & -0.033 & $-0.338^{* *}$ \\
& $(0.114)$ & $(0.102)$ & $(0.129)$ & $(0.120)$ \\
\hline
\end{tabular}

Table 3: Probit regressions on impatience and violations of stationarity for individual and collective decisions $(N=220)$.

Note: Reported figures are the marginal effects. Significant at ${ }^{*} 5 \%,{ }^{*} 1 \%$.

Individual impatience differed between the main and both the REPETITION and the INFORMED PLANNER treatments. In the latter treatment, the greater impatience observed when an individual member is deciding for the group - based on one straw poll of member preferences - might well be due to a composition effect. As described previously, subjects in the INFORMED PLANNER treatment were individually more impatient than in the main experiment. It is therefore possible that the information included in the straw poll might have reduced the impatience of group outcomes to a greater extent than was observed in the INFORMED PLANNER treatment. The observed difference in impatience between the main experiment and the REPETITION treatment (described in the next paragraph) is the most difficult to explain because their designs differed only in that the latter excluded group decisions. In particular, both treatments required that each subject come to the laboratory three times at regularly scheduled intervals. If the scheduling ability of subjects led to our experiment to suffer from a selection bias as regards impatience, then we should have observed no difference between the main experiment and the REPETITION treatment as well as significant differences between that experiment and the three 
other additional treatments; however, these outcomes did not obtain. Finally, we remark that collective decisions in the INFORMED PLANNER treatment replicate Jackson and Yariv's (2014) finding that the decisions made by a benevolent planner does not satisfy stationarity when the planner is herself affected by those decisions.

Luhan et al. (2009) show that individual behavior can be changed simply by learning and repetition. To explore the possibility of our results being confounded by this dynamic, we set up a REPETITION treatment that replicates the experiment with $N=20$ individuals. This treatment was identical to the main experiment except that subjects made twice as many individual decisions (across all three sessions) and were not involved in any collective decision; for the instructions, see Appendix $\mathrm{D}$ for the instructions). We found no individual-level differences between the two repeated decisions in any of the three sessions $(p=0.34)$.

\section{Discussion and conclusions}

This paper presents a within-subject longitudinal laboratory experiment on collective time preferences. We are the first to study four properties of time preferences - impatience, stationarity, age independence, and dynamic consistency - for both individuals and groups. In addition, we have designed a collective mechanism that helps groups coordinate on a decision. Our main findings are that: (i) individuals were impatient and tended not to behave in a manner consistent with constant discounting; (ii) groups made patient and highly consistent decisions; and (iii) the decision process made subjects converge to dynamically consistent decisions that satisfied both stationarity and age independence. Furthermore, the patient decisions made by groups indicate that the discount factors of groups are more in line with market interest rates than are the discount factors of individuals.

Our results show that individuals gravitate toward making patient decisions when placed in an environment broader than one delineated by purely individual decisions. This generalization is robust to all the decision contexts that we implemented. First, under our coordination mechanism based on majority voting preceded by a deliberation phase, almost every subject moved toward a patient 
vote regardless of his group's composition and of his own preferences. Second, our robustness checks confirmed that, absent the deliberation phase, simple-majority voting was also followed by collective choices exhibiting more patience than individual choices (although the effect was weaker in that non-deliberating context). The shift toward patience was evident also when subjects served in the social planner role - whether informed or uninformed about others' preferences. This result speaks to the long-standing debate over the ethics of social discounting and to more recent results from evolutionary theory. For instance, Robson and Szentes (2014) argue that individuals exhibit more patience when decisions are made collectively owing to a difference between individual and group evolutionary selection.

A participant with full access to perfect credit markets should not display any violation of the conditions on time preferences, from which it follows that choices made at the individual level should be stationary and dynamically consistent. Yet because our groups have no existence outside the laboratory, there is no reason to believe that access to credit justifies patient, stationary and/or dynamically consistent choices. In fact, we obtain precisely the opposite result: choices are more consistent and patient at the group level than at the individual level. This finding leaves open the source of violations at the individual level. One possible explanation could be that the greater deliberation time associated with a group decision helps reduce individuals' errors. Any such cognitive spillover effect would presumably have spanned the three experimental sessions, so individual violations should no longer be evident in Sessions 2 and 3; however, the results were not compatible with that hypothesis. Another possible explanation is instability at the individual level. That all three conditions (stationarity, dynamic consistency, age independence) were violated at the individual level on only half on the measures strongly suggests unstable intertemporal preferences for at least some individuals. We affirm the call of Meier and Sprenger (2015) for future research on how best to identify individuals with unstable preferences in choice over time.

One limitation of this research is that the experimental design we implemented could have influenced the main results. A typical drawback in experiments that elicit time preferences is the uncertainty of future payoffs (Halevy, 2015; Augenblick et al., 
2015). Having uncertain prospects could raise the impatience levels for subjects, whose time preferences may then begin to incorporate a risk premium (Halevy, 2008; Epper et al., 2011; Baucells and Heukamp, 2012; Epper and Fehr-Duda, 2012). We took such uncertainty out of play by offering high monetary payoffs and guaranteeing payment through bank transfers by the National Public Treasury. Although that approach could have tilted the scales toward behavior that is more patient, we believe that the benefits of this incentive structure outweigh its drawbacks.

Another possible limitation is that some of our results could be explained by a selection bias. In our experiment - as in most experiments seeking to develop longitudinal measures - subjects were asked to commit to multiple (here, three) sessions over an extended time period (here, 8 weeks). Our subjects thus share the ability to schedule time commitments (Frederick, 2005; Dohmen et al., 2010; PerezArce, 2011). Even so, the proportion of dynamically consistent individual choices that we found is no higher than what has been reported in the literature. ${ }^{10} \mathrm{We}$ remark that the additional treatment used to test the effect of repeated decisions was based on an identical scheduling of sessions and likewise indicated no such selection bias. Finally, consider that this selection bias would probably influence all decisions to a similar extent and so would have little effect on the difference between individual and collective decisions.

A third limitation of our experimental design is that indifference values above $y$ ( $€ 100$ in individual decisions and $€ 500$ in collective decisions) could not be chosen. Because indifference values were thus censored at $y$, our experiment ruled out the the possibility of negative time preferences. With regard to real-effort tasks, (Casari and Dragone, 2015) document that negative time preference can arise in a longitudinal experiment involving losses. Recall that our experiment addressed monetary gains only, for which negative discounting is less frequent than in the loss domain (Abdellaoui et al., 2013).

\footnotetext{
${ }^{10}$ Giné et al. (2014) find that 50\% of the choices satisfy stationarity and 35\% satisfy dynamic consistency. In Study 1 of Sayman and Öncüler (2009), the authors find no evidence favoring time inconsistency: $58 \%$ of the choices were dynamically consistent. Halevy (2015) report that $48 \%$ of time-consistent subjects and $56 \%$ of all subjects exhibit stationary preferences.
} 
We adopted majority voting as a procedure for coming to a group decision after a deliberation phase. ${ }^{11}$ In this context, majority voting corresponds to a coordination game and in theory can lead to multiple equilibria (Plott, 1967); hence we cannot rule out the possibility of strategic voting. When applied to collective time preferences, majority voting on the most immediate reward $x$ equivalent to a given delayed reward $y$ results in multiple equilibria provided that the group consists of more than three voters. Multiple equilibria arise also when agents have incomplete information about characteristics of the game structure (Myerson and Weber, 1993). As a result, anything can happen in equilibrium for such multicandidate elections (Palfrey, 2009). To help participants coordinate their choices on a unique equilibrium and avoid dominated equilibria, we added a deliberation phase based on successive straw polls. In a different setting, Brandts and Cooper (2006) show that feedback on other preferences could help overcome coordination failures. We find that choosing collectively patient choices made coordination easier - not only for groups in which most subjects agreed upon patience at the outset but also for groups in which patience was not initially the prevailing characteristic. This finding is evidence that information exchanges during the deliberation phase played a specific role in the final group outcome. Specifically, sharing information on voting intentions might have led individuals to vote against their own preference (a finding that could alternatively be explained by strategic voting; see Myerson and Weber, 1993). That result is consistent also with existing psychological evidence on group decisions (Stoner, 1968; Moscovici and Zavalloni, 1969; Schkade et al., 2000), with the literature on information exchange (Viscusi et al., 2011) and with both theoretical and empirical papers on polarization (Glaeser and Sunstein, 2009; Luhan et al., 2009; Sobel, 2014). When opinions are more polarized, more extreme group decisions are made as compared with the preferences of individual group members. According to our results, this observation can be explained by the relatively more patient subjects having the greatest influence on final decisions.

\footnotetext{
${ }^{11}$ Rather than voting on a common decision, subjects could have coordinated on a sharing rule (Millner and Heal, 2014). Because this alternative mechanism did not allowed for direct comparisons between individual and collective preferences, we opted for a political (voting) approach.
} 
Finally, our coordinating device of successive straw polls allowed groups to converge quickly on a given decision. In this respect, our results have implications for how boards and committees can achieve consistent decisions. A natural consequence of this coordinating device is the shifting of individual preferences. Almost all shifts were in the direction of increased patience - a tendency that was confirmed by the additional treatments. In comparison with individual decisions, collective decisions more often produced a consistent sequence of preference relations over time. 


\section{References}

Abdellaoui, M., H. Bleichrodt, and O. L'Haridon (2013): "Sign-dependence in intertemporal choice," Journal of Risk and Uncertainty, 47, 225-253.

Andreoni, J. And C. Sprenger (2012a): "Estimating Time Preferences from Convex Budgets," The American Economic Review, 102, 3333-3356.

(2012b): "Risk preferences are not time preferences," American Economic Review, 102, 3357-3376.

Augenblick, N., M. Niederle, And C. Sprenger (2015): "Working Over Time: Dynamic Inconsistency in Real Effort Tasks," The Quarterly Journal of Economics, 130, 1067-1115.

Baucells, M. and F. H. Heukamp (2012): "Probability and time trade-off," Management Science, 58, 831-842.

Benzion, U., A. Rapoport, And J. Yagil (1989): "Discount rates inferred from decisions: An experimental study," Management science, 35, 270-284.

Bleichrodt, H. And M. Johannesson (2001): "Time preference for health: A test of stationarity versus decreasing timing aversion," Journal of Mathematical Psychology, 45, 265-282.

Bleichrodt, H., K. I. Rohde, And P. P. Wakker (2008): "Koopmans' constant discounting for intertemporal choice: A simplification and a generalization," Journal of Mathematical Psychology, 52, 341-347.

(2009): "Non-hyperbolic time inconsistency," Games and Economic Behavior, 66, 27-38.

Bostic, R., R. J. Herrnstein, And R. D. Luce (1990): "The effect on the preference-reversal phenomenon of using choice indifferences," Journal of Economic Behavior \& Organization, 13, 193-212. 
Brandts, J. And D. J. Cooper (2006): "A change would do you good.... An experimental study on how to overcome coordination failure in organizations," American Economic Review, 669-693.

Caplin, A. And J. Leahy (2004): "The supply of information by a concerned expert," The Economic Journal, 114, 487-505.

Carlsson, F., H. He, P. Martinsson, P. Qin, and M. Sutter (2012): "Household decision making in rural China: Using experiments to estimate the influences of spouses," Journal of Economic Behavior \& Organization.

Casari, M. And D. Dragone (2015): "Choice reversal without temptation: A dynamic experiment on time preferences," Journal of Risk and Uncertainty, 50, $119-140$.

Charness, G. And M. Rabin (2002): "Understanding social preferences with simple tests," Quarterly journal of Economics, 817-869.

Charness, G. And M. Sutter (2012): "Groups make better self-interested decisions," The Journal of Economic Perspectives, 26, 157-176.

Coller, M. and M. B. Williams (1999): "Eliciting individual discount rates," Experimental Economics, 2, 107-127.

Cooper, D. J. And J. H. Kagel (2005): "Are two heads better than one? Team versus individual play in signaling games," American Economic Review, 477-509.

DellaVigna, S. (2009): "Psychology and Economics: Evidence from the Field," Journal of Economic Literature, 47, 315-372.

Denant-Boemont, L. And Y. Loheac (2011): "Time and Teams: An experimental Study about Group Inter-temporal Choice," Working Paper.

Dohmen, T., A. Falk, D. Huffman, And U. Sunde (2010): "Are Risk Aversion and Impatience Related to Cognitive Ability?" American Economic Review, 100, $1238-1260$. 
Epper, T. AND H. FeHr-Duda (2012): "The missing link: Unifying risk taking and time discounting," University of Zurich Department of Economics Working Paper.

Epper, T., H. Fenr-DudA, ANd A. Bruhin (2011): "Viewing the future through a warped lens: Why uncertainty generates hyperbolic discounting," Journal of Risk and Uncertainty, 43, 169-203.

Fishburn, P. C. And A. Rubinstein (1982): "Time preference," International Economic Review, 23, 677-694.

Forsythe, R., R. B. Myerson, T. A. Rietz, and R. J. Weber (1993): “An experiment on coordination in multi-candidate elections: The importance of polls and election histories," Social Choice and Welfare, 10, 223-247.

Frederick, S. (2005): "Cognitive reflection and decision making," The Journal of Economic Perspectives, 19, 25-42.

Frederick, S., G. Loewenstein, and T. O'donoghue (2002): "Time discounting and time preference: A critical review," Journal of economic literature, 40, $351-401$.

Gerardi, D. And L. YARIV (2007): "Deliberative voting," Journal of Economic Theory, 134, 317-338.

Giné, X., J. Goldberg, D. Silverman, And D. Yang (2014): "Revising Commitments: Field Evidence on the Adjustment of Prior Choices," working paper, World Bank.

Glaeser, E. L. And C. R. Sunstein (2009): "Extremism and social learning," Journal of Legal Analysis, 1, 263-324.

Goeree, J. K. And L. YAriv (2011): "An experimental study of collective deliberation," Econometrica, 79, 893-921. 
Gollier, C. And R. Zeckhauser (2005): "Aggregation of heterogeneous time preferences," Journal of Political Economy, 113, 878-896.

Halevy, Y. (2008): "Strotz meets Allais: Diminishing impatience and the certainty effect," American Economic Review, 1145-1162.

(2015): "Time Consistency: Stationarity and Time Invariance," Econometrica, 83, 335-352.

Holcomb, J. H. AND P. S. Nelson (1992): "Another experimental look at individual time preference," Rationality and Society, 4, 199-220.

Horowitz, J. K. (1992): "A test of intertemporal consistency," Journal of Economic Behavior \& Organization, 17, 171-182.

Jackson, M. And L. YARIV (2014): "Present Bias and Collective Dynamic Choice in the Lab," American Economic Review, 104, 4184-4204.

_ (2015): "Collective Dynamic Choice: The Necessity of Time Inconsistency," American Economic Journal: Microeconomics, 7.

KANG, M.-I. AND S. IKedA (2014): "Time discounting and smoking behavior: evidence from a panel survey," Health Economics, 23, 1443-1464.

Kirby, K. N. And N. N. Maraković (1995): "Modeling myopic decisions: Evidence for hyperbolic delay-discounting within subjects and amounts," Organizational Behavior and Human Decision Processes, 64, 22-30.

Loewenstein, G. And D. Prelec (1992): "Anomalies in intertemporal choice: Evidence and an interpretation," The Quarterly Journal of Economics, 573-597.

Luhan, W. J., M. G. Kocher, And M. Sutter (2009): "Group polarization in the team dictator game reconsidered," Experimental Economics, 12, 26-41.

Maciejovsky, B., M. Sutter, D. V. Budescu, and P. Bernau (2013): "Teams Make You Smarter: How Exposure to Teams Improves Individual Decisions in Probability and Reasoning Tasks," Management Science, 59, 1255-1270. 
Meier, S. And C. D. Sprenger (2015): "Temporal stability of time preferences," Review of Economics and Statistics, 97, 273-286.

Millner, A. And G. Heal (2014): "Resolving Intertemporal Conflicts: Economics vs Politics," Tech. rep., National Bureau of Economic Research.

Moscovici, S. And M. Zavalloni (1969): "The group as a polarizer of attitudes." Journal of personality and social psychology, 12, 125.

Myerson, R. B. AND R. J. Weber (1993): "A theory of voting equilibria," American Political Science Review, 102-114.

Noussair, C., S. Robin, And B. Ruffieux (2004): "Revealing consumers' willingness-to-pay: A comparison of the BDM mechanism and the Vickrey auction," Journal of economic psychology, 25, 725-741.

Palfrey, T. R. (2009): "Laboratory experiments in political economy," Annual Review of Political Science, 12, 379-388.

Perez-Arce, F. (2011): "The Effect of Education on Time Preferences," Working paper, RAND Corporation.

Phelps, E. S. And R. A. Pollak (1968): "On second-best national saving and game-equilibrium growth," The Review of Economic Studies, 185-199.

Plott, C. R. (1967): "A notion of equilibrium and its possibility under majority rule," The American Economic Review, 787-806.

Read, D., S. Frederick, And M. Airoldi (2012): "Four days later in Cincinnati: Longitudinal tests of hyperbolic discounting," Acta psychologica, 140, 177-185.

Robson, A. J. And B. Szentes (2014): "A Biological Theory of Social Discounting," American Economic Review, 104, 3481-3497.

Rohde, K. I. (2010): "The hyperbolic factor: A measure of time inconsistency," Journal of Risk and Uncertainty, 41, 125-140. 
SAmuelson, P. A. (1937): "A note on measurement of utility" The Review of Economic Studies, 4, 155-161.

Sayman, S. AND A. ÖNCÜLer (2009): "An investigation of time inconsistency," Management Science, 55, 470-482.

Schaner, S. (2015): "Do opposites detract? intrahousehold preference heterogeneity and inefficient strategic savings," American Economic Journal: Applied Economics, 7, 135-174.

Schkade, D., C. R. Sunstein, And D. Kahneman (2000): "Deliberating about dollars: The severity shift," Columbia Law Review, 1139-1175.

Schram, A. J. (2004): Experimental public choice, Springer.

Shapiro, J. (2010): "Discounting for You, Me, and We: Time Preference in Groups and Pairs," Working Paper.

Sobel, J. (2014): "On the relationship between individual and group decisions," Theoretical Economics, 9, 163-185.

Stoner, J. A. (1968): "Risky and cautious shifts in group decisions: The influence of widely held values," Journal of Experimental Social Psychology, 4, 442-459.

Strotz, R. H. (1955): "Myopia and inconsistency in dynamic utility maximization," The Review of Economic Studies, 23, 165-180.

TAkeuchi, K. (2011): "Non-parametric test of time consistency: Present bias and future bias," Games and Economic Behavior, 71, 456-478.

Thaler, R. (1981): "Some empirical evidence on dynamic inconsistency," Economics Letters, 8, 201-207.

Viscusi, W. K., O. R. Phillips, And S. Kroll (2011): "Risky investment decisions: How are individuals influenced by their groups?" Journal of Risk and Uncertainty, 43, 81-106. 
WÖlbert, E. AND A. RIEDL (2013): "Measuring time and risk preferences: Reliability, stability, domain specificity," CESifo Working Paper $n^{\circ} 4339$.

Zuber, S. (2010): "The Aggregation of Preferences: Can We Ignore the Past?" Theory and Decision, 70, 367-384. 


\section{Appendix A Indexes}

This appendix reports values of the indexes of violation of stationarity (Table 4), dynamic consistency (Figure 4), and age independence (Figure 5).

\begin{tabular}{ccc}
\hline \hline & \multicolumn{2}{c}{ Stationarity } \\
\hline measured & at $t$ & at $t+\Delta$ \\
\hline Individuals & 0.883 & $2.121^{*}$ \\
Groups & -0.417 & 0.583 \\
\hline \hline
\end{tabular}

Table 4: Violations of stationarity for individuals and groups.

Note: Reported figures are the average values of indexes (no violation corresponds to a value of zero). Significant at $* 5 \%$.

\begin{tabular}{cccccc}
\hline \hline & Dynamic Consistency & \multicolumn{3}{c}{ Age Independence } \\
\hline measured & at $t+\Delta$ & at $t+2 \Delta$ & from $t(1)$ & from $t(2)$ & from $t+\Delta$ \\
\hline Individuals & 1.103 & $-3.357^{* *}$ & 2.017 & -1.161 & $3.224^{*}$ \\
Groups & -0.683 & -0.950 & -1.100 & -0.367 & -0.100 \\
\hline \hline
\end{tabular}

Table 5: Violations of dynamic consistency and age independence for individuals and groups.

Note: Reported figures are the average values of indexes (no violation corresponds to a value of zero). Significant at ${ }^{*} 5 \%,{ }^{* *} 1 \%$. 


\begin{tabular}{cccccccc}
\hline \hline & \multicolumn{2}{c}{ Stationarity } & \multicolumn{2}{c}{ Dynamic Consistency } & \multicolumn{3}{c}{ Age Independence } \\
\hline measured & at $t$ & at $t+\Delta$ & from $t(1)$ & from $t(2)$ & from $t+\Delta$ & at $t+\Delta$ & at $t+2 \Delta$ \\
\hline Planner & 0.800 & $2.533^{*}$ & 0.689 & $-3.844^{*}$ & 1.489 & -1.311 & $3.222^{*}$ \\
\hline \hline
\end{tabular}

Table 6: Violations of stationarity, age independence and dynamic consistency - Utilitarian criterion based on the sum of individual values.

Note: Reported figures are the average values of indexes (no violation corresponds to a value of zero). Significant at $* 5 \%$. 


\section{Appendix B Experimental Instructions}

The experiment was conducted from January to March 2012 at LABEX-EM, the experimental lab of the University of Rennes. Subjects were recruited using the ORSEE (Greiner, 2004) software, and the experiment was run using a purposewritten software coded in Z-tree (Fischbacher, 2007). In the recruitment phase, subjects were informed that they would be required to participate in three successive experimental sessions scheduled at regular (four-week) intervals. Before entering the lab, subjects had to confirm their willingness to make that commitment. The rest of this appendix translates into English the instructions that participating subjects received.

\section{General Instructions}

Thank you for participating in our experiment. During this experiment, you will have to make decisions involving various amounts of money. If you follow the instructions, you could win quite a large amount of money. All your responses will be converted into anonymous data after the experiment. During the experiment, you must answer a series of choice questions. There are no right or wrong answers to these questions. We are interested in your preferences: the only right answer to a choice task is the choice that you prefer.

Twenty people will participate in this experimental session. During the session, you will have to make decisions individually and collectively. Therefore, you will decide alone on some decisions and will interact with other participants on other decisions. For reasons of anonymity, you will not have access to the other participants' identities.

The experiment consists of two parts:

- in the first [second] part, you will decide as an individual;

- in the second [first] part, you will make a decision in common as a member of a group of five people (i.e., you and four other people). 


\section{Gains and Payment}

Your final payment will be determined by the choices you made during the experiment. For your participation, you will receive a show-up fee of $€ 20$. This fee is conditional on your participation in the three experimental sessions. The show-up fee will be paid at the end of the third experimental session only if you attend all three of the sessions.

During the experiment, you will be asked to answer a series of choice questions regarding different amounts of money available at different dates. The display represented in Figure 7 gives an example of one such series. Option A offers a fixed amount of $€ 100$ to be obtained in 4 weeks' time. Option B offers a series of six amounts, equally ranged between $€ 50$ and $€ 100$, to be obtained tomorrow. For each of the six amounts, you will be asked to indicate whether you would like to choose option A or option B. Once you have switched between option A and option B, a scrollbar will appear on the screen. The scrollbar allows you to refine the amount of money at which you switch your choice from A to B. For instance, suppose you switch at $€ 72$.

If you switch at $€ 72$, do you agree that you prefer to choose option $\mathrm{B}$ at a higher amount than $€ 72$ ? $(\mathrm{Y} / \mathrm{N})$. Do you agree that you prefer to wait 4 weeks and choose option $A$ at prices lower than $€ 72$ ? (Y/N). If you have any questions, please feel free to ask the experimenter.

The payment will be implemented as follows. At the end of each experimental session, four participants will be selected at random from among the twenty participants attending the session. For each of these participants, the computer will select one decision at random. For that decision, the computer will select one possible choice at random. Let's take the decision represented in Figure 7 as an example. For that decision, an integer between 50 and 100 will be selected at random.

If the computer draws 63 , then the selected choice is between $€ 63$ tomorrow and $€ 100$ in 4 weeks' time. Do you agree? (Y/N). If you chose $€ 72$ as a switching point, then your selected choice is therefore $€ 100$ in four weeks' time and you will receive your payment directly by bank transfer from the National Treasury within 4 weeks. 
Do you agree? $(\mathrm{Y} / \mathrm{N})$.

Suppose that instead the computer draws 83; then the selected choice is between $€ 83$ tomorrow and $€ 100$ in 4 weeks' time. Do you agree? (Y/N). If you chose $€ 72$ as a switching point, then your selected choice is therefore $€ 83$ tomorrow and you will receive your payment directly by bank transfer from the National Treasury tomorrow. Do you agree? (Y/N). If you have any questions, please feel free to ask the experimenter.

At the end of the experimental session, you will get a receipt from the University of Rennes 1 for the payment.

\section{Individual Decisions}

For these decisions, you will have to reply alone to a series of choice questions regarding different amounts of money available at different dates. The display represented in Figure 7 shows an example of a series of questions. Option A offers a fixed amount of $€ 100$ to be obtained in 4 weeks' time. Option B offers a series of six amounts, equally ranged between $€ 50$ and $€ 100$, to be obtained tomorrow. For each of the six amounts, you will be asked to indicate whether you would like to choose option A or option B. Once you will have switched between option A and option B, a scrollbar will appear. The scrollbar allows you to refine the amount of money at which you switch your choice from A to B.

Once you will have selected a switching point, you can continue by clicking on "OK". You can also cancel your choice. When you click on "OK", a confirmation screen will appear and you can proceed with the next decision.

\section{Collective Decisions}

For collective decisions, you will have to reply in groups of five to a series of choice questions regarding different amounts of money available at different dates. For these decisions, a display similar to the one represented in Figure 9 will appear. This display will allow you to communicate with the other members of the group before deciding as a group. All the collective amounts will be shared equally among 
the group members. For collective decisions, the majority rule will apply: for each choice, whenever at least three of the five members agree, their choice will be adopted by the group. The decision will be made after four successive displays of voting intentions for each group member and a final vote. Groups will remain the same for all decisions; in other words, you will make a group decision with the same people each time. For reasons of anonymity, you will be identified by a color for each decision. Colors will be reshuffled randomly between each decision.

For the first trial, you will be presented with a display similar to the one represented in Figure 8. Option A offers a fixed amount of $€ 500$ to be obtained by the group in four weeks' time. Option B offers a series of six amounts, equally ranged between $€ 250$ and $€ 500$, to be obtained by the group tomorrow. For each of the six amounts, you will be asked to indicate whether you would like the group to choose option A or option B. Once you have switched between option A and option B, a scrollbar will appear. The scrollbar allows you to refine the amount of money at which you switch your choice from A to B. Suppose you switch at $€ 350$.

If you switch at $€ 350$, do you agree that you prefer the group to choose option B at a higher amount than $€ 350$ ? $(\mathrm{Y} / \mathrm{N})$. Do you agree that you prefer the group to wait four weeks and choose option A at a lower amount than $€ 350$ ? (Y/N). If you have any questions, please feel free to ask the experimenter.

Once you have selected a switching point, you can continue by clicking on "OK". When you click on "OK", your opinion will be sent to the other members of the group and you will get their opinions.

The results of the trial will be displayed along with the next decision to be made (Figure 9).The display will enable you to see the opinions of the other members of the group. The results of the previous trial will show you, for each possible choice between option A and option B, whether or not a majority has been reached. After four successive trials, the decision you make will be the final vote for your group. After that decision, the result of the vote will appear (Figure 10). The screen will display the votes of each member, the group switching point, and your share. Suppose that the decision of your group led to a switching point of $€ 349$. If your group switches at $€ 349$, do you agree that a majority of members prefer to 
choose option B at a higher amount than $€ 349$ ? (Y/N). Do you agree that, if the selected amount is lower than $€ 349$ amount, you would get your share which is 100 euros in 4 weeks times? Do you agree that a majority of the members would prefer to wait 4 weeks and get option A at a lower amount than 349 euros? (Y/N). Do you agree that, if the selected amount is equal to $€ 472$ (higher than $€ 349$ ), you would get your share, which is $€ 83.6$ tomorrow? If you have any questions, please feel free to ask the experimenter.

Once your group has made a decision, you can proceed with the next decision. 


\section{Appendix C Displays}

This appendix shows the typical displays used in the experiment. Figure 7 shows the multiple-choice list used to elicit indifference points; Figure 8 shows the equivalent multiple-choice list used to elicit indifference points for the first straw poll. Figure 9 displays the information each subject received at the end of each sequence. Figure 10 shows the final screen presented to the subject after a vote.

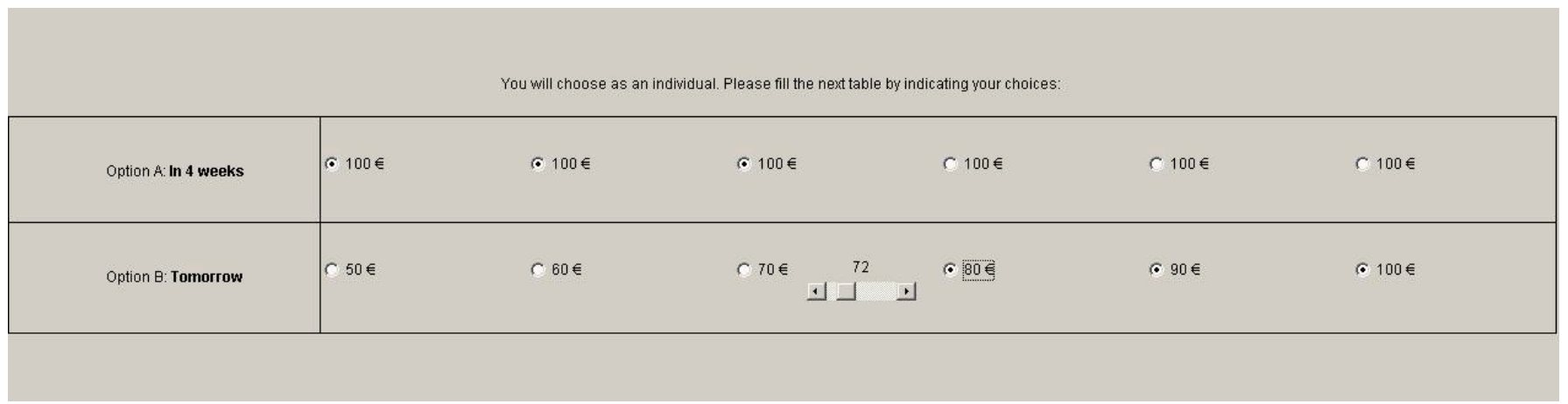

Figure 7: Presentation of choice list in individual decisions.

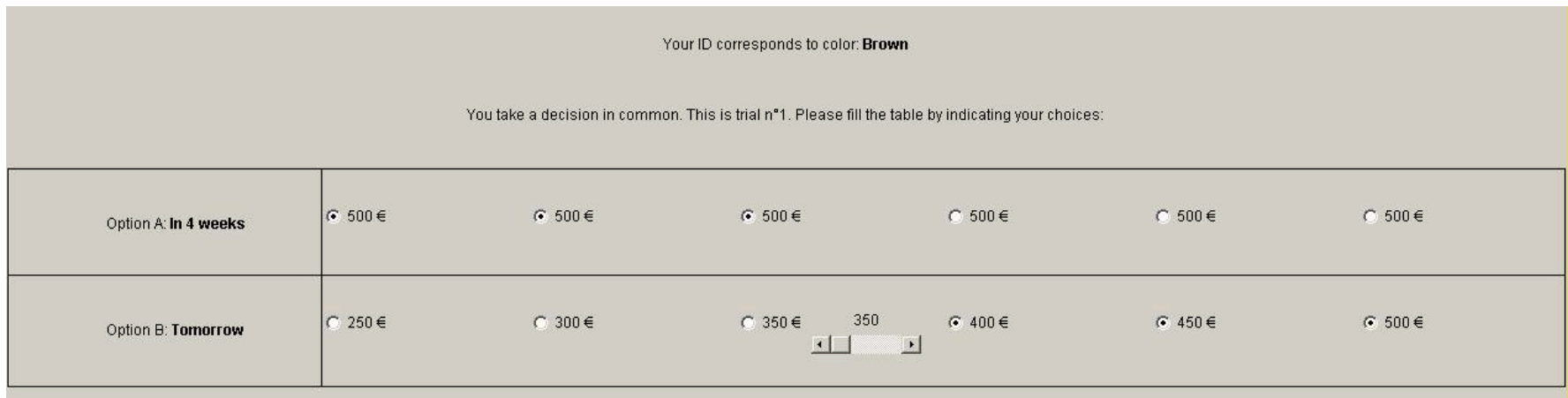

Figure 8: Presentation of choice list in collective decisions - First straw poll. 
Your ID corresponds to color: Brown

You take a decision in common. This is the fith and last trial, and it will determine your final choice. Please fill the following table by indicating your choices:

\begin{tabular}{|c|c|c|c|c|c|c|}
\hline Option A: In $\mathbf{4}$ weeks & C $500 €$ & C $500 €$ & C $500 €$ & C $500 €$ & C $500 €$ & C $500 €$ \\
\hline Option B: Tomorrow & C $250 €$ & $C 300 €$ & $C 350 €$ & C $400 €$ & C $450 €$ & C $500 €$ \\
\hline Brown & 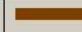 & & $353 €$ & & & \\
\hline Blue & 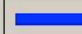 & & & & & \\
\hline Purple & 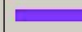 & & & 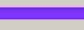 & & \\
\hline Grey & 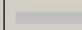 & 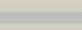 & $341 €$ & & & \\
\hline Beige & & & & & & \\
\hline
\end{tabular}

Figure 9: Information given about other member preferences during the group decision process.

Here are the final results for the group:

\begin{tabular}{|c|c|}
\hline Group Members & $\begin{array}{c}\text { Minimum amount requested for option B in order to } \\
\text { leave option A (by increasing rank) }\end{array}$ \\
\hline Beige & 261 \\
\hline Blue & 347 \\
\hline Gray & 349 \\
\hline Brown & 390 \\
\hline Purple & 438 \\
\hline
\end{tabular}

The total amount chosen by the group is $\mathbf{3 4 9 €}$

This decision gives you individually $69.80 €$

Figure 10: Presentation of a collective decision. 


\section{Appendix D Experimental Instructions: Ad- ditional Treatments}

The instructions in the additional treatments were based on those described previously in Appendix B. Here we list the changes in those instructions for each treatment.

\section{REPETITION treatment}

- lines 18-26: Twenty people will participate in this experimental session. During the session, you will have to make decisions individually.

The experiment consists of two parts:

- in the first part, you will decide as an individual;

- in the second part, you will decide as an individual.

- lines 79-130: deleted.

\section{VOTING treatment}

- lines 29-32: For your participation, you will receive a show-up fee of $€ 4$

- lines 87-88: deleted

- lines 90-91: deleted

- line 92: For the first trial deleted

- lines 105-111: The decision you make will be the vote for your group. Once you have selected a switching point for the vote, you can continue by clicking on "OK".

\section{INFORMED PLANNER treatment}

- lines 18-26: Twenty people will participate in this experimental session. During the session, you will have to make decisions individually for yourself and for a group. Therefore, you will decide for yourself on some decisions and for you and other participants on other decisions. For reasons of anonymity, you will 
not have access to the other participants' identities.

The experiment consists of two parts:

- in the first [second] part, you will decide as an individual;

- in the second [first] part, you will decide for a group of five people (i.e., you and four other people).

- lines 29-32: For your participation, you will receive a show-up fee of $€ 4$

- lines 80-81: For collective decisions, you will have to reply for a group of five to a series of choice questions regarding different amounts of money available at different dates.

- lines 84-88: ... before making a decision for the group. All the collective amounts will be shared equally among the members of the group. Each member of the group will make his/her choice for the group. Payments will be based on the decision of one member of the group chosen at random. The decision will be made after one display of opinions for each group member.

- line 92: For the first trial deleted

- lines 109-112: After this display, the decision you take will be your decision for the group. After that decision the result of your choice will appear.

- lines 115 and 117: you replaces a majority of members

- line 123: Once you have made a decision, you can proceed with the next decision.

\section{UNINFORMED PLANNER treatment}

The changes for this treatment are the same as those just described for the INFORMED PLANNER treatment plus the following changes for lines 80-115.

- lines 80-88: For collective decisions, you will have to reply for a group of five individuals to a series of choice questions regarding different amounts of money available at different dates. All the collective amounts will be shared equally among the members of the group. Each member of the group will make his/her 
choice for the group. Payments will be based on the decision of one member of the group chosen at random.

- line 92: For the first trial deleted

- lines 105-114: After your decision, the result of you choice will appear.

\section{Appendix E Results for the Additional Treat-}

\section{ments}

For the REPETITION treatment, a decision maker was classified as impatient (resp. patient) if at least four of six indifference values yielded an impatient (resp. patient) answer; otherwise, the decision maker was classified as mixed. For the remaining additional treatments (Voting treatment, INFORMED PLANNER treatment, UNINFORMED PLANNER treatment), a decision maker was classified as impatient (patient) if at least two out of three indifference values yielded an impatient (patient) answer. The classifications are presented in Table 7 . Tables 8 to 11 report additional results on stationarity, dynamic consistency, age independence, shape of impatience and distance to individual preferences.

\begin{tabular}{ccccc}
\hline \hline Treatment & Condition & Impatient & Patient & Mixed \\
\hline \multirow{2}{*}{ REPETITION } & initial answer & $80 \%$ & $15 \%$ & $5 \%$ \\
& repeated answer & $75 \%$ & $15 \%$ & $10 \%$ \\
\hline \multirow{2}{*}{ VOTING } & individual & $80 \%$ & $20 \%$ & - \\
& group & $75 \%$ & $25 \%$ & - \\
\hline \multirow{2}{*}{ INFORMED } & individual & $83.3 \%$ & $16.7 \%$ & - \\
PLANNER & for the group & $67.7 \%$ & $33.3 \%$ & - \\
\hline UNINFORMED & individual & $75 \%$ & $25 \%$ & - \\
PLANNER & for the group & $80 \%$ & $20 \%$ & - \\
\hline \hline
\end{tabular}

Table 7: Classification of answers under the additional treatments. 


\begin{tabular}{|c|c|c|c|}
\hline Treatment & Condition & measured at $t$ & measured at $t+\Delta$ \\
\hline \multirow[t]{2}{*}{ REPETITION } & initial answer & 3.35 & 1.47 \\
\hline & repeated answer & 0.50 & 0.105 \\
\hline \multirow[t]{2}{*}{ VOTING } & individual & 0.10 & - \\
\hline & group & $4.73^{*}$ & - \\
\hline INFORMED & individual & 0.35 & - \\
\hline PLANNER & for the group & $3.34^{* *}$ & - \\
\hline UNINFORMED & individual & -0.65 & - \\
\hline PLANNER & for the group & 0.09 & - \\
\hline
\end{tabular}

Table 8: Violations of stationarity.

Note: Reported figures are the average values of indexes (no violation corresponds to a value of zero). Significant at ${ }^{*} 5 \%,{ }^{* *}$ at $1 \%$.

\begin{tabular}{cccccc}
\hline \hline & Dynamic Consistency & \multicolumn{3}{c}{ Age Independence } \\
\hline measured & at $t+\Delta$ & at $t+2 \Delta$ & from $t(1)$ & from $t(2)$ & from $t+\Delta$ \\
\hline Initial answer & -4.210 & 1.790 & -0.421 & 2.842 & 3.263 \\
Repeated answer & -1.053 & 2.053 & -0.790 & 1.368 & 2.158 \\
\hline \hline
\end{tabular}

Table 9: Violations of dynamic consistency and age independence in the repeated treatment.

Note: Reported figures are the average values of indexes (no violation corresponds to a value of zero). 


\begin{tabular}{ccccc}
\hline \hline Treatment & Condition & $\begin{array}{c}\text { Increasing } \\
\text { Impatience }\end{array}$ & $\begin{array}{c}\text { Constant } \\
\text { Impatience }\end{array}$ & $\begin{array}{c}\text { Decreasing } \\
\text { Impatience }\end{array}$ \\
\hline \multirow{2}{*}{ REPETITION } & Initial answer & $5 \%$ & $10 \%$ & $85 \%$ \\
& repeated answer & $20 \%$ & $10 \%$ & $70 \%$ \\
\hline \multirow{2}{*}{ VOTING } & Individual & $30 \%$ & $13.3 \%$ & $56.7 \%$ \\
& Group & $16.7 \%$ & $16.7 \%$ & $66.7 \%$ \\
\hline \multirow{2}{*}{ INFORMED } & individual & $28.3 \%$ & $16.7 \%$ & $55 \%$ \\
\hline PLANNER & for the group & $15 \%$ & $30 \%$ & $55 \%$ \\
\hline PLINFORMED & individual & $40 \%$ & $20 \%$ & $40 \%$ \\
\hline \hline
\end{tabular}

Table 10: Classification of individuals and groups by shape of impatience.

\begin{tabular}{cccc}
\hline \hline Treatment & Identical decisions & More patient & Less patient \\
\hline & & & \\
\hline VOTING & $22.2 \%$ & $51.1 \%$ & $26.7 \%$ \\
INFORMED PLANNER & $31.7 \%$ & $57.2 \%$ & $11.1 \%$ \\
UNINFORMED PLANNER & $28.3 \%$ & $46.7 \%$ & $25 \%$ \\
\hline \hline
\end{tabular}

Table 11: Distance to individual preferences. 